\title{
The Influence and Application of Confucian Management Philosophy on Brand Inheritance
}

\author{
Yuening Li \\ Faulty of Business \\ City University of Macau \\ Macau, China 999078
}

\begin{abstract}
Confucian philosophy of management is a treasure in Chinese traditional culture. It constructs the core value of Confucianism and establishes its historical status. In the historical records Confucian management philosophy can be traced back to the pre-Qin period, which is based on the essential features and value orientation of cultivating moral characters of people and making people peaceful. Its core ideas cover the content of benevolence and rites. After more than two thousand years of criticism and succession, the Confucian thought has merged the modern and world advanced elements and brought the new from the old to form the Confucian management philosophy, which has been used for reference for the rapid economic rise of the Asian countries, such as Japan and Korea, and the economic development of the European and American countries. However, in the eyes of Chinese people, the Confucian management philosophy is often marked by backwardness and feudalism. We are more willing to use the western management model and management thought in the management of the company, and the management and inheritance of the brand. In fact, the maximization of the utility of Confucian management philosophy is the combination of "ancient for the present" with modern management mode and the western management mode, to create a management theory which is in line with the national conditions, and to integrate it with the inheritance of the brand better, which is the substantive utility of the modernization of Confucian managers.
\end{abstract}

Keywords-Confucianism; management philosophy; brand inheritance; influence; application

\section{INTRODUCTION}

Confucianism is an indispensable part of Chinese traditional culture. There are a lot of management philosophy worthy of praise and reference. In essence, the Confucian thought is to publicize and teach the lofty way of administering the country. As time goes by, the world is filled with the way of management. More and more countries in the world have discovered and verified that the Confucian management philosophy has a strong practicability and reference for the rise and development of the economy. The Confucian management philosophy, which has more than two thousand years of history, is constantly enriched, modernized and regionalized, breaking the national boundaries and exerting its greatest utility. It is also the direction of the future development of Confucian management philosophy. The paper has analyzed the influence and application of Confucian thought of Confucian management philosophy on "benevolence", "cultivating moral characters of people and making people peaceful", "rites" and "keep seeking change" on the brand inheritance and discussed the important practical significance of Confucian management philosophy on modern management, especially the brand inheritance.

\section{THE MAIN BODY OF THE THESIS}

\section{A. The Connotation of Confucian Management Philosophy}

Chinese Confucianism is a cultural school guided by the thought of Confucius in the Spring and Autumn Period. Confucianists believe good nature and good humanity ${ }^{[1]}$. Its main ideas are filial piety, order, loyalty, faith, rite, benevolence, honesty and humiliation, and the core is benevolence. It can also be understood as moral thoughts, such as fraternity, well-being, fairness, justice, honesty, trustworthiness, revolution, innovation, civilization, harmony and rule of law ${ }^{[2]}$. In terms of the essential characteristics and value orientation of Confucianism, its core ideas are mainly divided into four aspects

First, the Confucian philosophy of "taking benevolence first" is the "people-oriented" Confucian philosophy of management. The core of Confucian theory is "benevolence". As the first ancestor of Confucianism, Confucius preached and explained lessons in his life. The most important thing he referred was benevolence. In ancient times, ancient people often put their own good or bad fortune on the heaven, but neglected the role of human beings. As a guiding cultural school, the Confucian thought had unearthed the importance of people early. It changed people's sight from the heaven on man. It advocated benevolence and kindness. "The benevolent inconsiderate neighbors, and achieve themselves and benefit others at the same time", "do not do to others what you would not have them do to you", "to govern a country with one thousand military vehicles, it is necessary to conscientiously handle national events and abide by credit, honesty and no bullying, saving financial expenses and loving officials and officials, so that the people should not be misused for farming" and other Confucian thoughts analyze the relationship of people, which is a spirit of feeling for others and considering others. This shows that "benevolence" and "man" are inseparable. These ideas of humanism are the most primitive "people-oriented" thought in Confucianism. At that time, we 
have already had the humanistic care management philosophy. "Loving people" is the essence of the Confucian thought of "benevolence".

Second, the Confucian philosophy of "cultivating moral character of people and making people peaceful" is a Confucian management philosophy of "being upright". "Cultivating moral character of people and making people peaceful" is put forward on the basis of benevolence. "To be benevolent, one shall overcome his selfish desires and follow the rite. Once people can do this, the country will be peaceful". "Both emperor and common people shall cultivate their moral characters". Ancient people's self-cultivation to correct self, understand completely, have good faith and a just heart, manage family and country affairs and make the country peaceful. Modern people's self-cultivation has remarkable characteristics in the actual management. "Cultivating moral characters" and "making people peaceful" can be explained separately, and the two aspects interact each other. "To cultivate moral characters" requires managers to pay attention to self-cultivation and self-control, occupying the primary position of all management activities and the main basis of "making people peaceful". In contrast, "making people peaceful" is essentially realized through the effective management style of "cultivating moral characters", and is the ultimate goal to be achieved in the management activities. Confucius said: "if one is upright, his subordinates will follow him without command. If one is not, his subordinates will not follow him even with command". Taking "cultivating moral characters, managing family and country affairs and making people peaceful" as self duty is Confucian thought, which is precious wisdom of management. In terms of Confucianists, it is fundamental to cultivate one's moral character. Only by following such a way, the managers can achieve the ultimate goal of "making people peaceful" by self-cultivation and selfimprovement.

Third, it is the Confucian management philosophy of treasuring rite. It refers to courtesy, good manners, comity, formality, etiquette and social institutions. Rite includes three parts, form, rule and system. Rite and benevolence are mutually exclusive. Confucius said, "man is not benevolent, and how can him be polite? Man is not benevolent, and how can him be happy?" The ritual culture advocated by Confucianists is "to obey by God's will, follow the rite and depend on benevolence". Paying attention to rite is the traditional virtue of China as a "state of ceremony". In the view of Confucianism, the reason why people are human, different from animals, is because of "man has rites but animals don't". People have been gregarious species since ancient times. With the advancement of time, the evolution of species formed modern social life. In other words, man is always in the social activities, and not divorced from the organization. So in a well ordered social organization, we should abide by and perform a series of behavior norms. These behavior norms are the socalled "rites" in the view of Confucianism.

Fourth, keeping seeking change is the Confucian philosophy of management. In the Confucian classics Yi Jing, there was a "law of the world". It means all things in the universe are in the changing transformation. Only by following the law, can we make all things forward, progress, innovate, and they will not stagnate. In addition, the "Yi" in the Yi Jing means "varied, easy and simple". "Variation" has the meaning of elucidation, change and adaption ${ }^{[3]}$. Yijing Xici recorded: "if things go to the ultimate, man will think to change. Change brings versatility and duration". "The lower and the upper are changeable. Hard stems and soft stems transform. Changes are surface, and the thing causing changes is essence". Confucius said, "someone can learn together with me, but they may different ambition. Someone can have same ambition with me, but they may change their determination. Someone can be determined with me, but they may not weigh up the matter carefully". This shows the importance of the change. But this kind of adaptability not only emphasizes "change", but also "keep". Keep the change in a steady way. Too much is as bad as too little. The change should revolve around a constant principle and seek the way and method of the change.

\section{B. The Impact of Globalized Commodity Market on Brand Inheritance}

Jesper Kunder, a Danish brand expert, points out that the world is entering a new era of value economy from the old productive economy era, and the enterprises in the era of new value economy should operate with brand orientation. Nowadays, world brands can improve the quality of people's lives, and brands can also reflect a complete life style and values. The inheritance of brand has an immeasurable value and significance for increasing product characteristics, strengthening brand spirit and consolidating its high price in segmented market. In the international market, brands with high reputation and products sold all over the world generally have the following characteristics. The brands have a long history. Some even have decades or even a hundred years of history. They often can lead the development direction of the industry and have the knowledge to support them.

There is a unique story behind each brand, and there will be a history of its own brand. Some brands are old but fresh, while some disappear as a flash in the pan, which is bound to be related to the market renewal effect and the management concept. The globalized commodity market means that the choice scope and way of consumers have surpassed national boundaries and entered a larger commodity market. The following is that consumer demand has become more complex and uncertain, and personalization is becoming more and more prominent. The global commodity market is an inevitable trend of economic and technological development. The trends put the brand in a more complex, uncertain and unbalanced market, breaking the original closed market environment, bringing more resources and opportunities, but also bringing more challenges. So the choice of brand positioning and whether to adhere to the original brand values, respect the history of the brand are related to the inheritance of brand. It is easy to start, but hard to stick to. The enterprise shall make the correct choice under this kind of fierce competition environment, carefully consider the different regional environment, different customs, different technology innovation and brand development strategies, under the dynamic market environment, constantly adjust the brand strategy, and gain recognition of markets and consumers in brand quality, service and social responsibilities on the basis of 
adhering to brand values and principles. In this game, the vast number of brands eventually will drown in the tide. So, the impact of the global commodity market on brand inheritance is the reality that we have to face.

\section{The Value Presentation of Brand Inheritance}

Brand is the distinction between enterprises. Brand is also a sign to highlight the personality and get the public support. Brand is a label for the enterprise to obtain the global market share. Brand is a magic weapon to keep the vitality of the enterprise. As long as a brand is familiar to the public, shares a certain proportion of the global market share, has loyal customers, then it means that the life cycle of the brand will be everlasting. The inheritance of the brand is a long process, and it takes a long time to accumulate. It may take several generations to work together to achieve it. These brands are different from "fast food brand" which chase vested interests and get quick profit in the short term. For benefit, they can produce products far from the original sales theme, and change their face overnight. It has proved that the vast majority of "fast food brands" cannot withstand the long-term test from market and the public. They wither away fast, and successful cases are few. The inheritance of brand is not a casual behavior in a short time, but through the accumulation of quality, reputation and image in a word-of-mouth manner. The global market environment is changing rapidly. In order to obtain more customers' favor and market share, the brand has to expand the product line, update the brand packaging, product variety, product taste and even expand overseas market. But the original source of the brand is the core value that cannot be changed in the changeable environment. As it changed, it disappeared. The process of brand inheritance is not stagnant. It needs to be inherited by generation to generation. In the process, it develops the new from the old and presents its inheritance value, forming a lasting brand accumulation in customer's heart. Generally speaking, the value of brand inheritance can be summed up in three aspects as follows:

First is to embody the personality influence of the brand. Personality is the soul of a brand, and there is a unique story behind every brand and even every product. When the consumer understands the story and history behind its brand or product, including how it struggles in the natural competitive environment, how it traces its source and how it seeks innovation in the tradition, then users will treat it as a piece of art full of historical accumulation and catering to the trend of the times rather than a simple and well product. As a result, brand personality is becoming more and more distinct, and its competitiveness will also be enhanced, leaving a deep impression on consumers' minds. For example, the Virgin Group, founded by the famous British businessman Richard Branden, is famous for its unique belief that "everything can be done and all conditions can be created." From 1970 to 2013, the Virgin Group gradually became the largest private enterprise in Britain. It owned more than 200 large and small companies, involving aviation, finance, railways, records, wedding dresses and so on, like half a national production department, and its recognition reached $96 \%$.

Second is to strengthen the cohesion and binding force of the brand. The inheritance of the brand has gone through a long journey. After several generations of managers and employees, the inheritance of brand history is like a strong adhesive, closely connecting all strata, leaders and employees in the organization. For example, in the economic depression, the Panasonic group firmly didn't reduce the staff. This inheritance power touches every staff and inspires their sense of honor, responsibility and initiative, so that they have one heart to achieve the goals and ideals of the company. In addition, the inheritance of the brand is an intangible constraint force, playing its function through the establishment of rules and regulations and the formation of moral norms. It encourages employees to consciously inherit the tradition, standardize their own words and deeds, and always pursue the spirit of brand inheritance.

Third is to continue the vitality of the brand. The brands with long life cycle do not necessarily have the conditions of brand inheritance, but the long life circle is the indispensable factor for brand inheritance. The life course of the brand is of great significance and value. It not just tells the consumer what the brand has experienced in the past, but also shows why the brand has today's orientation and the future development direction. In fact it is actually a strategic management, which a brand shall pay attention to. This brand inheritance is to prove to consumers that the brand is up to the test and is trustworthy. Why consumers are loyal to the brand is because the brand is willing to listen to opinions of consumers no matter what class they are in the society. It attaches importance to the needs of consumers, and don't mind whether they buy their products. The brand respects for consumers' ideas and tastes, and is willing to make changes. The brand believes that they will win a large number of royal audiences by listening, thinking highly of and respecting consumers. Thus, the brand will be continued and inherited in a virtuous circle. Therefore, only by respecting the history and respecting the consumers can a brand survive forever.

\section{The Practical Significance of Confucian Management Philosophy to Brand Inheritance}

First is to guide the brand inheritance from the perspective of relationship creation and maintenance and with the theory of "human-oriented" human plasticity. The core content of the Confucian management philosophy is "benevolence", and its management theory is based on the plasticity of human nature, and the Confucian management philosophy is essentially a practical process of stimulating the moral goodness of human beings and maintaining the harmonious and stable development of the society. The philosophical thought of "benevolence" is injected into the connotation of the brand, combining the Confucian management philosophy with the brand management. In the concrete management practice, it is to realize the moral rationality of human nature, and reflect the process of human nature from being molded to completion in the whole process. The management of the brand is inseparable from the management of the people involved in it. In modern management, it is to manage and coordinate interpersonal relationship most. The process of management and coordination is a process to understand people and stimulate creativity and subjective initiative, which is the essence of management. This kind of people-oriented brand 
inheritance and the core connotation of Confucian management philosophy have different approaches but equally satisfactory results.

Therefore, the brand inheritance should reflect the strength of "benevolence", mainly in three aspects: the demands of the employees, the loyalty of consumers, and the coordination of interpersonal relations. First, in terms of staff demands, we cannot think of staff as simple "economic man", but also take into consideration people's thoughts, demands and coordination of interpersonal relations, so as to "benefit both people and myself, take if people are willing and not take if people aren't willing". Finally, achieve the ultimate goal and help others achieve themselves in coordination of interpersonal relations, and reach the realm of invincible benevolence.

Secondly, in the pursuit of consumers' loyalty, we should give the brand a profound and rich connotation, establish a distinct brand positioning, and make full use of all kinds of effective internal and external communication channels to form high recognition of consumers on the brand, create brand belief, and eventually form a strong brand loyalty. Keller, a famous American brand research expert, puts forward to perceive the brand value based on the brand relationship of the consumer. He believes that the strong brand is of high value because it not only has high popularity, but also has a deep relationship with the consumer, that is, it can let the consumer experience the interests it represents. Once the consumer connects the brand to the tangible and intangible benefits they can obtain, the consumer will stop to buy, be loyal to the brand and are willing to pay a higher price for it. Many scholars directly indicate that loyal customers will be the main source of competitive advantage of enterprise $\mathrm{e}^{[4]}$.

Finally, a harmonious member relationship also helps to meet the needs of the members for interpersonal relationship. That is to say, act to be polite, tolerant, honest, quick and generous, and that is benevolent and people-oriented. The plasticity of good human nature can be sued to enhance the cohesion of the brand and the commitment of organization and improve the creativity and competition of the brand to the greatest extent. The talents that the manager needs are not only people who pursue performance indifferently, thus achieving the maximization of self-interest, but people who care about the organization from the heart and share honor and disgrace with the organization. In the process of achieving management goals, managers should allow staff to use their own methods, and could give supervision and guidance in the side, never impose their ideas on employees, and let employees comply with their own instructions, or else the cohesiveness of the organization will be discounted.

Second is to guide the brand inheritance with the theory of "self-cultivation and peace keeping" and from the perspective of relationship building and influence. In fact, good managers can lead the brand farther. The managers who are difficult to control themselves and manage themselves are difficult to be expected. How long can a brand go? How far can it go? It is all unknown and how to inherit and extend a brand. In a sense, management is to set an example. It shows that the management philosophy of self-cultivation and peace keeping has an important practical significance for the brand inheritance. The positive significance of the thought of "selfcultivation and peace keeping" to modern management can be manifested in two aspects: on one hand, it is "to cultivate one's moral characters and manage talent", which is a good way of guiding management. For the manager, good moral cultivation can call staff and form a consistent, healthy and upward orientation of value in the scope of management. On the other hand, it is a management mode of staff following the example of their superiors. Under guidance of good moral cultivation, managers carry out by acts and lead the whole situation, which has effective positive guidance to employees. It is a living management method. To play management function of this philosophy, managers should pay attention to the infiltration and transformation from the flexible management state to the institutionalized management and from the image shaping of "self-cultivation and peace keeping" to the integration of the democratic supervision ${ }^{[5]}$.

Being engaged in industry for 20 years, Shibuzawa Eichi learned from our Confucian tradition and said that business is not for individual, but for society. This is the best way to realize the ideal personality. For lifetime, he insisted on traveling and learning. He put his thinking of managing business for society into his business. His book Analects and Abacus is an important book to change social value of Japanese. Konosuke Matsushita, the founder of Panasonic, took the philosophy of running-water management as the social mission of the Panasonic brand, and became the life meaning of all the Panasonic. It was not the interests of the shareholders, but to the society and the country, which is consistent with Shibuzawa Eichi's philosophy of managing business for society. From the origin of the thought of benefiting three parties, Konosuke Matsushita learned from others and family, and finally realized the mission of his own brand, and passed this mission to everyone in the Panasonic and passed this mission to the present. It takes lifelong employment system and the system of the annual performance and order. It is the best words and symbols of Japanese enterprises. Panasonic thinks that only the employees are happy, the enterprise will succeed, and the brand will be passed down.

It can be seen that after a hundred years and thousands of years, the brand still stays firm, active in the front of the modern market, and receive support of staff, because it runs through the Confucian management philosophy of "selfcultivation and peace keeping".

Third is to guide the brand inheritance with the theory of "taking rites as the best" and from the perspective of respect and regulation of relationship. Rite played a normative function on moral behavior in feudal society. However, obeying "rite" in ancient times is not only a requirement for ordinary people, but also a requirement for the rulers to comply with the ritual system, and it is an important basis for them to cultivate themselves. In other words, in the development of today's society, employees in the enterprise should be constrained by rules and regulations and moral norms. Whether the relative managers keep the rules or not, will also be supervised by the staff and the society. This is the key to the success of its support, the establishment of a good 
public image and the success of the implementation of the management strategy.

Then, the application of the Confucian manager philosophy of taking rite as the best to the brand inheritance should be guaranteed by the system and the ethics to restrict and standardize the behavior of the employees. This restriction and norms are not simply a means of violence, but a humanized supervision and guidance. Thus, form the value of taking rite as the best silently. Behavior Identity Manual and relevant work manuals of well-known companies are carried out from the top to the bottom, and regulate staff of all levels. Especially for new employee, the companies also made manual for new employee to guide new employee detailedly. It is said that nothing can be accomplished without norms or standards. Written regulations can be employees' standards and guidance in work to avoid careless mistakes in work process and technology. Each employee is a member of a large family, representing the overall behavior norms and mental features. It is necessary to set up a guide manual for the staff to have a deeper understanding of the brand culture and spirit, and they can more actively and joyfully integrate into the brand culture and participate in decision-making.

Fourth is to see brand extension and control from the perspective of "changelessness" and "changing". It, in facts, is the relationship between inheritance and innovation. They are not opposite and separated. The mission of inheritance is innovation, so it shall reflect both inheritance and innovation in passing down. It doesn't mean we should follow the old ways, which will reduce attraction of the young and the middle-aged, and thus cause the structural fault of the product's consumption6. Why the world's famous brands are able to live forever is not only because they produce products that meet the needs of people, but also because they are well versed in the mysteries of expansion. No matter what, no brand can be stopped. It shall develop. Einstein once said, "a man who never makes mistakes must never have tried anything new".

But the expansion of the brand is an adventure. Many brands failed in the extension and product line extension. Only a few brands survive. Does it make a difference when brand expands to new fields? Does it have a real competitive advantage? Does it cause damage to its core brand? In the process of brand extension, once it deviates from the original brand positioning, it will blur the positioning of the original brand, which will bring trouble to consumers, greatly affecting the extension of the brand. At the same time, it will also affect the sales of existing products. Therefore, change is the only constant brand belief, which is a golden rule. In today's globalized market, the brands with profound history and inheritance course actually have some eternal beliefs which support the brands to occupy certain market shares and are regarded as brand assets people cannot buy with money.

\section{CONCLUSION}

Confucianism has been a moral standard upholding in all aspects of society since Emperor Wudi put forward the idea of "banning hundred schools and respecting Confucianism". The Confucian philosophy of management not only has an extremely important reference for management in China, but also for western management lost in materialism, rationalization and institutionalization for a long time.

At the same time, a brand can survive forever, and it needs the accumulation and inheritance of history and culture. The success of Coca-Cola, as a famous brand in the world, owes to the integration of American spirit in brand, so that it is called as one of three major cultures together with freedom and democracy. Brand can enhance the social value of a country and become the spokesman of the country. For enterprises, having market share is more important than having a Morgan building, and the only way to obtain the market is to have a brand with market advantage, and in the future brand will be the core of the sustainable development of enterprise. It is of epoch-making and cross-border practical significance to perfectly combine Confucian management philosophy and brand inheritance and apply it in brand inheritance.

\section{REFERENCES}

[1] Wang Bangxiong. Learning Emotion Management from Confucianism and Taoism. Jianxing Culture Publishing Co., Ltd., 2010: 10. 王邦雄.向 儒道思想学情绪管理[M].健行文化出版事业有限公司,2010:10.

[2] Chen Tao, Wei Yongmei \& Long Lu. Influence of Confucian Culture on Corporate Culture and Brand Building. Modern Property (Midmonth Journal), 2012, 11 (11): 35-37. 陈涛,魏咏梅,龙露.儒家文化对企业文 化与品牌建设的影响研究 [J]. 现代物业(中旬刊),2012,11(11):35-37.

[3] Zhang Ying. Confucian Culture and Modern Development. Northern Literature (Late Month), 2016 (09): 168. 张颖.浅谈“儒家”文化与现代 发展[J/OL].北方文学(下旬),2016(09):168

[4] Keller, K.L. Strategic Brand Management - Building Measuring, and Managing Brand Equity. New York: Prentice Hall, 1998.

[5] Niu Weidong. Characteristics of Confucian Management Philosophy and its Contemporary Approach. Qiu Suo, 2013 (11): 114-116.牛卫东. 儒家管理哲学特质及其当代进路[J].求索,2013(11):114-116.

[6] Dai Xuegang. Research on Marketing Efficiency of Brand Inheritance Enterprises in the New Consumer Economy Era. Business Era, 2014 (17): 65-66.代学钢.品牌传承企业在新消费经济时代的营销效益研究 [J].商业时代,2014(17):65-66. 